\title{
Age estimation of brown shrimp Crangon crangon: comparison of two approaches applied to populations at the biogeographic edges
}

\author{
Joana Campos ${ }^{1,2, *}$, Ana Bio1 ${ }^{1}$, Vânia Freitas ${ }^{1,2}$, Cláudia Moreira ${ }^{1}$, Henk W. van der Veer ${ }^{2}$ \\ ${ }^{1}$ CIMAR/CIIMAR - Centro Interdisciplinar de Investigação Marinha e Ambiental — Universidade do Porto, \\ Rua dos Bragas 289, 4050-123 Porto, Portugal \\ ${ }^{2}$ Royal Netherlands Institute for Sea Research, PO Box 59, 1790 AB Den Burg Texel, The Netherlands
}

\begin{abstract}
In this study, 2 methods for age estimation of Crangon crangon were compared: one based on total length, the other based on the number of segments in the antennules, as suggested by Tiews' findings (1954: Ber Deut Wiss Kommiss 13:235-269). Shrimps from populations near the species' geographic edges, from Valosen Estuary (Norway) in the north and the Minho Estuary (Portugal) in the south, were used. These showed great individual variability in shrimp size growth and in antennule segment number increment, due to the presence of fast- and slow-growing shrimps in the 2 populations, implying that shrimps of different ages may have similar sizes, as well as similar segment numbers. Additionally, the origin of shrimp population, sex, length and segment number, and water temperature were found to influence growth, both in the length- and the segment-increment models, often being interacting parameters. Both methods resulted in growth curves similar to a typical von Bertalanffy growth curve. The growth rate was higher for females than for males and positively related to temperature; the maximum size was also larger for females. In contrast, maximum segment number was larger for males than for females, as has also been found by Tiews (1954). The 2 models resulted in considerably different age estimates, particularly for older shrimps (i.e. shrimps of larger size or with more antennule segments). The models also suggest site-specific growth rates. Any age estimation approach will therefore need to be validated for each population.
\end{abstract}

KEY WORDS: Crangon crangon $\cdot$ Age estimation $\cdot$ Growth $\cdot$ Moult $\cdot$ Temperature $\cdot$ Latitude

\section{INTRODUCTION}

The brown shrimp Crangon crangon (L.) is one of the most abundant crustacean species occurring in European shallow waters from the White Sea in the north of Russia to Morocco, and throughout the Mediterranean and Black Seas (Campos \& Van der Veer 2008). Despite this wide geographic distribution, only 4 distinct phylogeographic groups have been described - the northeastern Atlantic, the western Mediterranean, the Adriatic Sea and the Black Searevealing a strong population structure (Luttikhuizen et al. 2008). The species is also a very valuable fisheries resource and has, therefore, motivated exten- sive studies, especially at the centre of its distribution, around the North Sea. In past investigations on C. crangon growth, cohort analysis was applied at a local scale to estimate growth under natural conditions (Marchand 1981, Boddeke et al. 1985, Henderson \& Holmes 1987, Beukema 1992, Cattrijsse et al. 1997, Duran 1997, Cowx et al. 1998, Oh et al. 1999, Burrows et al. 2001, Viegas et al. 2007). Yet, the nearly year-long reproduction and continuous migration with increasing size makes cohort tracking very complicated. In other field studies, maximum growth was assumed and model predictions were applied to analyse life history patterns (Kuipers \& Dapper 1984, Temming \& Damm 2002). However, maximum growth 
requires optimum conditions, which under natural environments are seldom observed.

Results from these works cannot be generalized for the entire geographic range of the species, given the latitudinal compensation which has recently been described for the growth rate under controlled food and temperature conditions (Campos et al. 2009). Instead of a reduced growth rate of northern shrimps following the latitudinal thermal gradient, as would be expected (i.e. assuming that the lower temperature regime at higher latitudes slows down growth), a 'latitudinal compensation' was observed, whereby northern shrimps grew faster than shrimps from a southern population kept at the same temperature regime. In contrast, a recent field-based study near the southern limit of the species' distribution speculates that southern shrimps grow more slowly, mature earlier and have smaller brood sizes, and that their larvae have a more protracted settlement period than northern populations (Viegas et al. 2012). However, the comparison was made between non-contemporaneous studies, which limits conclusions, since inter-annual fluctuations in both shrimp abundance (Campos et al. 2010) and timing of biological stages are frequent (e.g. Oh et al. 1999).

Growth studies on crustaceans are further problematical because no hard structure related with age is retained throughout their lifespan (Hartnoll 2001): growth takes place by periodically shedding the hard exoskeleton in a process called moult or ecdysis. Accurate age estimation then requires growth experiments and/or tagging the animals. A morphological age estimation method, based on the number of 'growth bands' in the endocuticle of the base of the eyestalk or in the mesocardiac ossicle of the gastric mill of 4 decapod crustacean species, was proposed very recently by Kilada et al. (2012). Yet this method might be of limited application in short-lifespan species from warm waters (Kilada et al. 2012). Some attempts have been made with biochemical approaches, including the use of radionuclide ratios, the concentration of lipofuscin pigments in the brain and the structure of the infracerebral organ (Reyss et al. 1996, Hartnoll 2001, Castro et al. 2002, Harvey et al. 2010, Bosley \& Dumbauld 2011). Yet, the first method can only inform on the time since the last moult, the second requires calibration for each new study and might be affected by diet (Castro et al. 2002), and the third has only been studied for Nephrops norvegicus (Hartnoll 2001).

In contrast to these more laborious methodologies, Tiews' (1954) findings suggest a simple method to estimate the age of brown shrimp based on the presumed systematic increase of the number of seg- ments in the antennule with moulting, regardless of length increase. Tiews (1954) was able to relate the increase in the number of segments with moult events (which are related to shrimp's age), also considering water temperature and sex differences. Only 2 field studies (Schockaert 1968, Gelin et al. 2000) have applied Tiews' (1954) conclusions, though they ignored possible individual differences in growth conditions. In fact, no validation of this method has been performed so far in other populations. Yet, differences in growth and, hence, in length-at-age are expected for distant populations, suggesting that any age estimation method, whether based on length or segment numbers, has to be validated for the target population prior to its application.

In the present study, experiments on Crangon crangon growth and antennule segment increment were performed to test (1) whether a segment-based age estimation method (based on Tiews 1954) can be applied to populations at the geographic edges of the distribution and (2) whether the number of segments is an alternative, and better, age predictor than length. Shrimps came from 2 different locations representing the latitudinal range of $C$. crangon distribution: the Minho estuary, Portugal, near the southern limit of their distribution, and the Valosen estuary, Norway, at the northern limit. The relationships between daily growth and total shrimp length, and between antennule segment increment and segment number, were analysed and modelled considering shrimp population origin and sex as well as experimental temperature. Model results were then used to estimate age-length and age-segment number curves and to compare the 2 age estimation approaches.

\section{MATERIALS AND METHODS}

The data analyses presented here complement the information published in Campos et al. (2009) in which moult size increments and duration of the intermoult period, as well as growth rates, were individually followed to evaluate the existence of 'latitudinal compensation' in growth.

\section{Sampling}

Shrimps were caught in May 2006, at 2 locations: near the southern limit of the Crangon crangon (L.) distribution in the Minho estuary $\left(41^{\circ} \mathrm{N}\right)$, Portugal, and at its northern limit in the Valosen estuary $\left(67^{\circ} \mathrm{N}\right)$, Bodø, Norway (Fig. 1). Experimental shrimps 
were collected with a $1 \mathrm{~m}$ beam trawl, with $5 \mathrm{~mm}$ mesh size, in shallow areas of about 1 to $2 \mathrm{~m}$ water depth.

\section{Experimental setup}

Experiments were run in indoor facilities, at the CIIMAR (Porto, Portugal) and at the Høgskolen i Bodø (HIBO, Norway). Water temperature, salinity, light and food supply were controlled, and similar sampling, acclimatization procedures and experimental setups were used to minimize variability between sites.

Shrimps were collected 10 to $15 \mathrm{~d}$ before the start of the experiment. Smaller animals were selected and transferred randomly to 4 aerated seawater containers $(100 \times 30 \times 35 \mathrm{~cm})$ and kept individually within the container, separated from the others by a perforated plastic cage; no tagging or marking was necessary. In Portugal, seawater was initially set at $15^{\circ} \mathrm{C}$ with 32 psu salinity, and in Norway, at $7^{\circ} \mathrm{C}$ with $29 \mathrm{psu}$, corresponding to the field conditions found at the sampling sites at the time of collection. Conditions were gradually (within $3 \mathrm{~d}$ ) set to the levels of the trials, with water temperatures of 10, 15, 20 and $25^{\circ} \mathrm{C}\left( \pm 1^{\circ} \mathrm{C}\right)$, in each of the 4 containers, respectively, and with a salinity of 29 to 32 psu in all containers. Shrimps were subsequently allowed to acclimatize to the experimental conditions for $1 \mathrm{wk}$.

Animals were provided with excess food, supplied 6 to $7 \mathrm{~d} \mathrm{wk}^{-1}$. The food consisted of frozen or fresh mussel (Mytilus edulis) meat for human consumption (preventing the possible presence of toxic algae), which was stored in a cooler. Before feeding, any remaining food from the previous day was removed with tweezers.

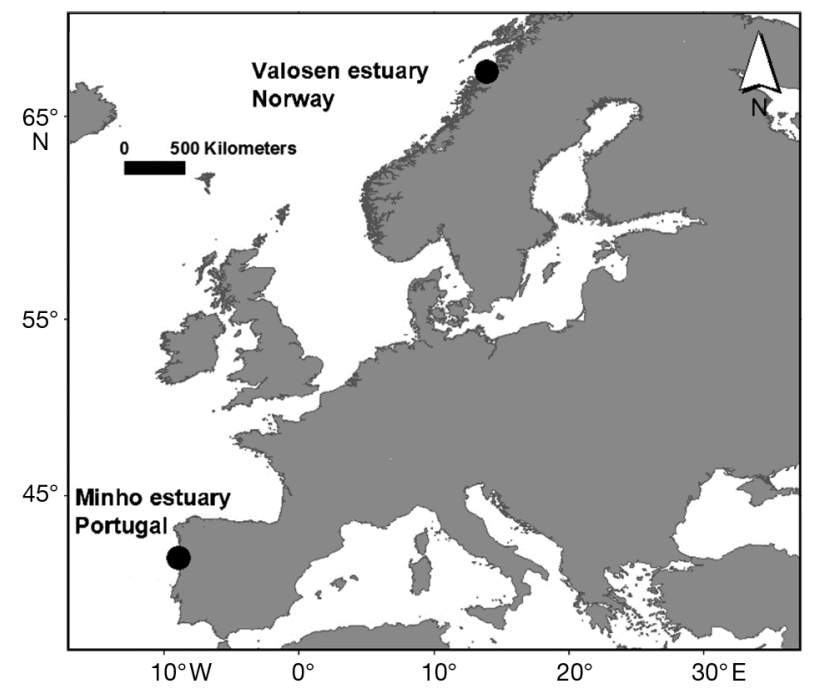

Fig. 1. Locations of the studied populations
Seawater was kept recirculated and changed, with water collected at a nearby location, 2 to 3 times a week to remove metabolic wastes. The bottoms of the aquaria were covered with a $5 \mathrm{~cm}$ layer of sediment taken from each location, which had been previously washed with seawater, dried for $5 \mathrm{~d}$ at $60^{\circ} \mathrm{C}$ and sieved through a $0.5 \mathrm{~mm}$ sieve. The photoperiod was set to $12 \mathrm{~h}$ light: $12 \mathrm{~h}$ darkness. Room temperature was kept at $15^{\circ} \mathrm{C}$ in Portugal and at $10^{\circ} \mathrm{C}$ in Norway. In each basin, temperature and salinity were controlled independently and checked daily. A cooler was used to maintain constant $10^{\circ} \mathrm{C}$ water temperature in Portugal, while no device was necessary in Norway; in the same way, no device was used for the $15^{\circ} \mathrm{C}$ treatment in Portugal. The other water temperature levels were maintained with water heaters.

After acclimatization, 5 sets of 5 females and 5 males were randomly selected from each container for the experiment. Gender was determined by observing the endopodite morphology on the first (larger and spoon-like in females) and second pleopods (bi-ramous in males) (Tiews 1954), under a binocular stereoscope, first in the live animal and later in the exuvia after every moult. Each day the animals were checked individually for exuvium, and, after each moult, the duration of the intermoult period was recorded, shrimp total length (from the tip of scaphocerites to the end of folded uropods) was measured ( $0.25 \mathrm{~mm}$ precision) by stretching the live or dead animal along a ruler, and the number of segments in the outer (shorter) flagellum of the antennule was counted (both in live animals and in their exuvia), using a binocular stereoscope. Shrimp were considered to have had zero growth when total length changed by $<0.25 \mathrm{~mm}$ between postmoult and premoult, and negative growth when total length decreased by $0.25 \mathrm{~mm}$ or more after moulting. Each shrimp that died during the experiment was replaced by another shrimp from a replacement pool. Shrimp mortality in the trials was higher in the 2 higher temperature treatments (Campos et al. 2009). The data included all periods between the first and last observed moult (considering all shrimps, unlike in Campos et al. [2009], where only shrimps measuring 20 to $39 \mathrm{~mm}$ were considered). The trial lasted for about $6.5 \mathrm{mo}$.

\section{Data analysis}

Length-growth and antennule-segment-increment models

A thorough exploration of data prior to regression modelling revealed a great deal of scatter, suggest- 
ing marked individual variability, even within the same experimental treatment and for similar shrimp sizes. Scatter plots considering data divided by shrimp origin (Valosen, Minho) and sex (male, female) suggested linear (first-order) relationships between shrimp growth rate $\left(\mathrm{GR}_{i} \mathrm{~mm} \mathrm{~d}^{-1}\right)$ and total length $(\mathrm{L} ; \mathrm{mm})$ and between antennule segment increment (SI; no. of segments $\mathrm{d}^{-1}$ ) and number of antennule segments (SN), with slopes depending on the experimental variables. We therefore used linear mixed effects models with first-order L or SN terms, using shrimp origin (O), sex (SEX) and temperature (T) as factors and considering the respective pairwise interaction terms.

Two approaches were taken: (1) global models including $\mathrm{O}$, SEX and $\mathrm{T}$ variables and (2) site- and sex-specific models using only data from one origin and sex. Model selection was backward, eliminating non-significant model terms. At each step, the least significant model term was removed and its significance tested. The procedure was repeated until all remaining model terms were significant. An exception was made whenever an interaction term was significant; its main effects were kept even if these were non-significant.

The initial global GR model contained GR as a response variable and $\mathrm{L}, \mathrm{T}$ and $\mathrm{SEX}$, as well as the interaction terms $\mathrm{L} \times \mathrm{T}, \mathrm{L} \times \mathrm{SEX}, \mathrm{L} \times \mathrm{O}, \mathrm{T} \times \mathrm{SEX}, \mathrm{T} \times$ $\mathrm{O}$ and SEX $\times \mathrm{O}$ as predictor variables. Initial originand sex-specific models were similar, but excluding origin and sex variables. Analogously, the initial SI model contained SI as a response variable and $\mathrm{SN}, \mathrm{T}$ and SEX, as well as the interaction terms $\mathrm{SN} \times \mathrm{T}$, $\mathrm{SN} \times \mathrm{SEX}, \mathrm{SN} \times \mathrm{O}, \mathrm{T} \times \mathrm{SEX}, \mathrm{T} \times \mathrm{O}$ and $\mathrm{SEX} \times \mathrm{O}$ as predictor variables. Site- and sex-specific models excluded site and sex variables.

Because data were obtained from repeated measurements, linear mixed effects (LME) models were applied using the R software 'nlme' packages (Pinheiro \& Bates 2000). We followed the modelling procedure proposed by Zuur et al. (2009): (1) regression considering the full model (i.e. model with all parameters and interaction terms) to get a general view of the relationships; (2) addition of the random component (to account for the repeated measurements), choosing from a random intercept or random intercept and slope model, with individuals nested or not in shrimp origin (for the global models); (3) application of a variance structure to deal with unwanted residual spread, considering identity, fixed, power, or exponential variance structures for the different explanatory variables; (4) selection of the fixed structure, eliminating non-significant model terms; (5) model validation; and (6) model prediction. Intermediate and final models were evaluated through residual analysis, and model selection (of the random term, variance structure and fixed structure) was based on likelihood ratio tests (with $\alpha=0.05$ ).

The goodness-of-fit of each model was estimated as the squared correlation between fitted and observed values, which is similar to an $\mathrm{R}^{2}$ (as suggested by $\mathrm{J}$. Pinheiro, co-author of the $\mathrm{R}$ 'nmle' package); the $\mathrm{R}^{2}$ measure commonly used in regression does not apply to a mixed model fit since the underlying estimation method is not least squares. This squared correlation was calculated for all of the model predictions and for predictions for shrimps of different origins, sexes, or temperature treatments, to assess on which data the model performed well or, possibly, failed. All analyses were done in R (R Development Core Team 2008).

\section{Age curves}

At this stage, it was impossible to know the real age of captured shrimps, but we did know the age difference between each moult, with its respective growth and segment-increment rates. Shrimp age-length curves could hence be established using our model estimates for growth; shrimp age-segment number curves were established based on the estimated antennule segment increments.

Starting with an initial length of $5 \mathrm{~mm}$ (settlement size) (Beukema 1992), assumed to occur at Day 0, daily growth was estimated using our global growth model and added to the initial length to obtain the length value for Day 1 . The length at Day 1 was used to estimate the length at Day 2, and so on, until a total age of about $3 \mathrm{yr}$ (approximate maximum longevity) was reached. The same procedure was applied to the SI model predictions, starting with 1 segment at Day 0. Next to the model predictions, the limits of a $95 \%$ confidence interval $(\mathrm{CI})$, i.e. predictions $\pm 2 \mathrm{SE}$ of the fit, were used to distinguish between fast- and slowgrowing shrimps. Using the same stepwise age estimate procedure, age curves based on the upper CI limit of the growth or segment-increment predictions were considered to represent fast-growing shrimps, and curves based on the lower CI limit were considered to represent slow-growing shrimps. Note that the point-wise CI for each daily prediction was very narrow, as daily GR and SI represent only a small fraction of shrimp lengths and segment numbers, respectively (about $0.5 \%$, on average). Growth- and segment-based age curves were compared, analysed in terms of shrimp origin, shrimp sex and tempera- 
ture level, and used to estimate the age of the experimental shrimps. Analyses were done in R (R Development Core Team 2008).

\section{RESULTS}

A total of 403 shrimps were used in the trials, 213 from Minho and 190 from Valosen; they experienced 2 to 18 moults during the experiment, totalling 1855 observed intermoult periods. The data distribution per experimental treatment is summarised in Table 1.

In general, shrimps from Valosen were larger and had more antennule segments (except for females kept at $15^{\circ} \mathrm{C}$ ) compared to those from Minho (KruskalWallis test: $\mathrm{p}<0.0001$ for both comparisons). Mean (Table 1) and median TL did not differ significantly (Kruskal-Wallis test: $\mathrm{p}=0.076$ ) between sexes (except for shrimp from Valosen, kept at $15^{\circ} \mathrm{C}$ ), whereas SN was lower for male than for female shrimp (Kruskal-Wallis test: $\mathrm{p}<0.0001$; Table 1). The SN per $\mathrm{mm}$ TL ranged between 0.51 and 0.59 for female and 0.70 and 0.82 for male shrimp.

Shrimps from Valosen tended to grow more than shrimps from Minho (Kruskal-Wallis test: $\mathrm{p}=0.003$ ) and females grew faster than males (Kruskal-Wallis test: $\mathrm{p}<0.000$ ), although there were many (up to $23 \%$ ) intermoult periods with zero growth and 8 with negative growth (1 female shrimp from Minho kept at $10^{\circ} \mathrm{C}$, 1 at $15^{\circ} \mathrm{C}$ and 2 at $25^{\circ} \mathrm{C}$, and 4 male shrimps from Minho kept at $25^{\circ} \mathrm{C}$ ), depending on shrimp ori- gin, sex and temperature (Table 1). SI was relatively similar across sexes and origin at 10 and at $20^{\circ} \mathrm{C}$, but quite variable for the other 2 temperature treatments. There was an increasing SI trend with increasing temperature, but no clear shrimp-origin or shrimpsex effects (Table 1).

\section{Growth and segment-increment models}

For all of the final models, the random effect of individual shrimps was significant; they were all LME models fitted by restricted maximum likelihood (REML). Model variables, coefficients and significances are presented in Tables 2 to 4 . For all GR models an exponential variance function for shrimp length performed best to improve the distribution of residuals. For all SI models, an exponential variance function for the number of antennule segments performed best and was used.

The global GR model was a random intercept and slope model, and the global SI model a random intercept model, neither with nesting of subject in location (Table 2). Considering the site- and sex-specific GR models (Table 3), a random intercept and slope model was found for female shrimps and a random intercept model was found for male shrimps from Minho. Site- and sex-specific SI models were all random intercept models, except for female shrimps from Valosen where a random intercept and slope model performed best (Table 4).

Table 1. Crangon crangon. Data summary statistics according to shrimp origin, sex and culture temperature (Temp). N: number of observed intermoult periods; TL: mean total length; SN: mean number of antennule segments; GR: mean growth; SI: mean segment increment; GR $\leq 0$ : percentage of intermoult periods with zero or negative growth (there were 8 periods with negative growth); $\mathrm{SI}=0$ : percentage of intermoult periods with zero segments added. Values in parentheses are standard deviations

\begin{tabular}{|c|c|c|c|c|c|c|c|c|c|}
\hline Origin & Sex & Temp $\left({ }^{\circ} \mathrm{C}\right)$ & $\mathrm{N}$ & TL (mm) & $\mathrm{SN}$ & $\mathrm{GR}\left(\mathrm{mm} \mathrm{d}^{-1}\right)$ & $\mathrm{SI}\left(\mathrm{d}^{-1}\right)$ & GR $\leq 0(\%)$ & $\mathrm{SI}=0(\%)$ \\
\hline \multirow[t]{8}{*}{ Minho } & Female & 10 & 101 & $28.3(8.5)$ & $14.8(4.1)$ & $0.08(0.07)$ & $0.06(0.04)$ & 15.8 & 15.8 \\
\hline & & 15 & 74 & $31.6(3.8)$ & $18.5(1.9)$ & $0.11(0.07)$ & $0.05(0.03)$ & 4.1 & 9.5 \\
\hline & & 20 & 218 & $31.3(10.2)$ & $17.1(5.1)$ & $0.16(0.11)$ & $0.10(0.08)$ & 10.1 & 12.4 \\
\hline & & 25 & 318 & $27.7(8.9)$ & $15.8(5.1)$ & $0.18(0.13)$ & $0.11(0.09)$ & 9.7 & 26.7 \\
\hline & Male & 10 & 60 & $26.7(6.2)$ & $19.3(5.1)$ & $0.07(0.07)$ & $0.06(0.05)$ & 23.3 & 15.0 \\
\hline & & 15 & 9 & $28.0(2.9)$ & $23.1(4.0)$ & $0.08(0.04)$ & $0.09(0.04)$ & 0.0 & 0.0 \\
\hline & & 20 & 191 & $29.2(6.9)$ & 20.7 (5.6) & $0.12(0.11)$ & $0.10(0.08)$ & 11.0 & 17.3 \\
\hline & & 25 & 185 & $27.5(5.6)$ & $19.5(5.2)$ & $0.13(0.10)$ & $0.10(0.09)$ & 11.9 & 22.7 \\
\hline \multirow[t]{8}{*}{ Valosen } & Female & 10 & 46 & $33.7(6.4)$ & $17.5(3.2)$ & $0.13(0.10)$ & $0.07(0.03)$ & 15.2 & 2.2 \\
\hline & & 15 & 72 & $33.8(8.2)$ & $17.1(4.3)$ & $0.21(0.12)$ & $0.12(0.06)$ & 2.8 & 1.4 \\
\hline & & 20 & 96 & $35.2(7.3)$ & $19.6(3.6)$ & $0.17(0.12)$ & $0.10(0.07)$ & 8.3 & 7.3 \\
\hline & & 25 & 96 & $35.1(7.1)$ & $17.6(3.4)$ & $0.25(0.16)$ & $0.13(0.08)$ & 6.3 & 3.1 \\
\hline & Male & 10 & 54 & $33.2(5.0)$ & $23.7(4.6)$ & $0.08(0.06)$ & $0.07(0.06)$ & 9.3 & 7.4 \\
\hline & & 15 & 102 & $36.6(6.3)$ & $25.7(5.3)$ & $0.13(0.09)$ & $0.10(0.08)$ & 6.9 & 8.8 \\
\hline & & 20 & 122 & $35.4(4.2)$ & $25.5(2.8)$ & $0.10(0.09)$ & $0.08(0.05)$ & 23.0 & 15.6 \\
\hline & & 25 & 111 & $35.1(4.2)$ & $24.3(3.1)$ & $0.16(0.12)$ & $0.09(0.08)$ & 9.0 & 32.4 \\
\hline
\end{tabular}


Table 2. Crangon crangon. Global model parameters, their coefficients and respective p-values, considering the fixed structure of the linear mixed effects model. GR: growth $\left(\mathrm{mm} \mathrm{d}^{-1}\right)$; SI: segment increment $\left(\mathrm{d}^{-1}\right)$; L: total shrimp length; T: temperature; SEX: shrimp sex; O: shrimp origin; SN: number of antennule segments; ns: not significant; ${ }^{*} p<0.05$; ${ }^{* *} p<0.01$; ${ }^{* * *} \mathrm{p}<0.001$. Temperature was modelled as a 4 -level factor

\begin{tabular}{|c|c|c|c|c|c|c|c|}
\hline \multirow{3}{*}{ Intercept } & \multicolumn{3}{|c|}{ Global GR model } & & \multicolumn{3}{|c|}{ Global SI model } \\
\hline & Value & $\mathrm{p}$ & & & Value & $\mathrm{p}$ & \\
\hline & 0.226 & $<0.001$ & *** & Intercept & 0.129 & $<0.001$ & *** \\
\hline $\mathrm{L}$ & -0.003 & 0.056 & ns & SN & -0.003 & 0.003 & ${ }^{* *}$ \\
\hline $\mathrm{T} 15^{\circ} \mathrm{C}$ & 0.183 & 0.004 & ** & $\mathrm{T} 15^{\circ} \mathrm{C}$ & 0.089 & 0.005 & ** \\
\hline T $20^{\circ} \mathrm{C}$ & 0.209 & $<0.001$ & *** & $\mathrm{T} 20^{\circ} \mathrm{C}$ & 0.107 & $<0.001$ & *** \\
\hline $\mathrm{T} 25^{\circ} \mathrm{C}$ & 0.256 & $<0.001$ & $* * *$ & $\mathrm{~T} 25^{\circ} \mathrm{C}$ & 0.105 & $<0.001$ & ${ }^{* * *}$ \\
\hline SEX male & 0.015 & 0.623 & ns & SEX male & 0.012 & 0.010 & ** \\
\hline O Minho & -0.142 & $<0.001$ & *** & O Minho & -0.076 & $<0.001$ & *** \\
\hline $\mathrm{L} \times \mathrm{T} 15^{\circ} \mathrm{C}$ & -0.003 & 0.057 & ns & $\mathrm{SN} \times \mathrm{T} 15^{\circ} \mathrm{C}$ & -0.002 & 0.114 & ns \\
\hline $\mathrm{L} \times \mathrm{T} 20^{\circ} \mathrm{C}$ & -0.005 & $<0.001$ & ${ }^{* * *}$ & $\mathrm{SN} \times \mathrm{T} 20^{\circ} \mathrm{C}$ & -0.003 & 0.003 & ${ }^{* *}$ \\
\hline $\mathrm{L} \times \mathrm{T} 25^{\circ} \mathrm{C}$ & -0.005 & 0.001 & *** & $\mathrm{SN} \times \mathrm{T} 25^{\circ} \mathrm{C}$ & -0.003 & 0.005 & ** \\
\hline $\mathrm{L} \times \mathrm{SEX}$ male & -0.002 & 0.006 & $* *$ & & & & \\
\hline $\mathrm{L} \times \mathrm{O}$ Minho & 0.003 & 0.003 & ** & $\mathrm{SN} \times \mathrm{O}$ Minho & 0.003 & $<0.001$ & *** \\
\hline $\mathrm{T} 15^{\circ} \mathrm{C} \times \mathrm{O}$ Minho & -0.061 & 0.018 & * & $\mathrm{T} 15^{\circ} \mathrm{C} \times \mathrm{O}$ Minho & -0.050 & 0.001 & ** \\
\hline T $20^{\circ} \mathrm{C} \times \mathrm{O}$ Minho & 0.011 & 0.609 & ns & T $20^{\circ} \mathrm{C} \times$ O Minho & -0.007 & 0.585 & ns \\
\hline $\mathrm{T} 25^{\circ} \mathrm{C} \times \mathrm{O}$ Minho & -0.042 & 0.054 & ns & T $25^{\circ} \mathrm{C} \times \mathrm{O}$ Minho & -0.007 & 0.569 & $\mathrm{~ns}$ \\
\hline
\end{tabular}

Table 3. Crangon crangon. Site- and sex-specific growth model parameters, their coefficients and respective p-values, considering the fixed structure of the linear mixed effects model. Details as in Table 2

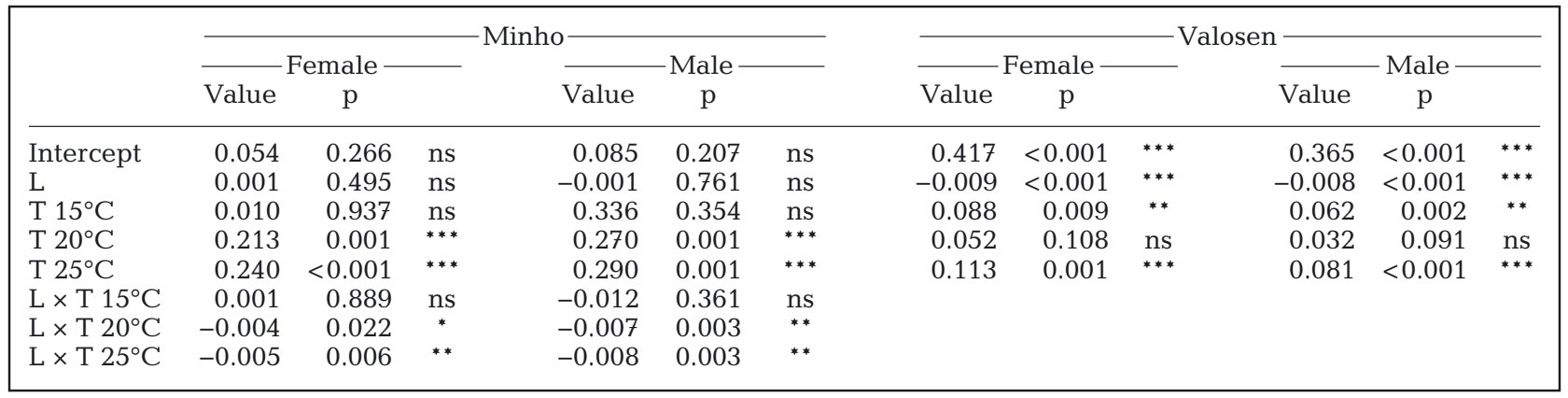

Table 4. Crangon crangon. Site- and sex-specific segment-increment model parameters, their coefficients and respective p-values, considering the fixed structure of the linear mixed effects model. Details as in Table 2

\begin{tabular}{|c|c|c|c|c|c|c|c|c|c|c|c|c|}
\hline & \multicolumn{6}{|c|}{$\longrightarrow$ Minho $\longrightarrow$} & \multicolumn{6}{|c|}{ _ Valosen } \\
\hline & \multicolumn{3}{|c|}{$\overline{\text { Female- }}$} & \multirow{2}{*}{ Value } & \multicolumn{2}{|c|}{-Male } & \multicolumn{3}{|c|}{ Female } & \multirow[b]{2}{*}{ Value } & \multicolumn{2}{|l|}{ Male } \\
\hline & Value & $\mathrm{p}$ & & & $\mathrm{p}$ & & Value & $\mathrm{p}$ & & & $\mathrm{p}$ & \\
\hline Intercept & 0.101 & $<0.001$ & *** & 0.125 & $<0.001$ & $* * *$ & 0.190 & $<0.001$ & ${ }^{* * *}$ & 0.167 & $<0.001$ & *** \\
\hline $\mathrm{SN}$ & -0.003 & $<0.001$ & $* * *$ & -0.003 & $<0.001$ & $* * *$ & -0.007 & $<0.001$ & ${ }^{* * *}$ & -0.004 & $<0.001$ & ${ }^{* * *}$ \\
\hline $\mathrm{T} 15^{\circ} \mathrm{C}$ & -0.001 & 0.907 & ns & 0.034 & 0.218 & $\mathrm{~ns}$ & 0.050 & 0.001 & *** & 0.035 & 0.004 & ** \\
\hline T $20^{\circ} \mathrm{C}$ & 0.043 & $<0.001$ & $* * *$ & 0.030 & 0.023 & * & 0.048 & $<0.001$ & ${ }^{* * * *}$ & 0.022 & 0.062 & ns \\
\hline T $25^{\circ} \mathrm{C}$ & 0.044 & $<0.001$ & ${ }^{* * *}$ & 0.035 & 0.009 & ${ }^{* *}$ & 0.061 & $<0.001$ & ${ }^{* * *}$ & 0.021 & 0.079 & ns \\
\hline
\end{tabular}

Apart from a few exceptions (see Figs. 2 \& 4), global models predicted decreasing growth with increasing shrimp size and less increase in the number of antennule segments with increasing segment number (Figs. 2 to 5, left column). In some cases growth prediction became negative for larger male shrimp. GR- and SI-predicted slopes were generally higher for Valosen than for Minho models. Comparing global GR and SI models, sex differences were clearer in the GR model, with non-overlapping CI for larger shrimp (except for shrimps from Minho cultured at 10 and $15^{\circ} \mathrm{C}$ ). The $\mathrm{L} \times \mathrm{SEX}$ intercept in the GR model further allowed different slopes between sexes for shrimp from the same origin, cultured at the same temperature. The CI were generally smaller for the SI than for the GR model predictions.

Site- and sex-specific models showed mostly predictions similar to those of the global models (Figs. 2 

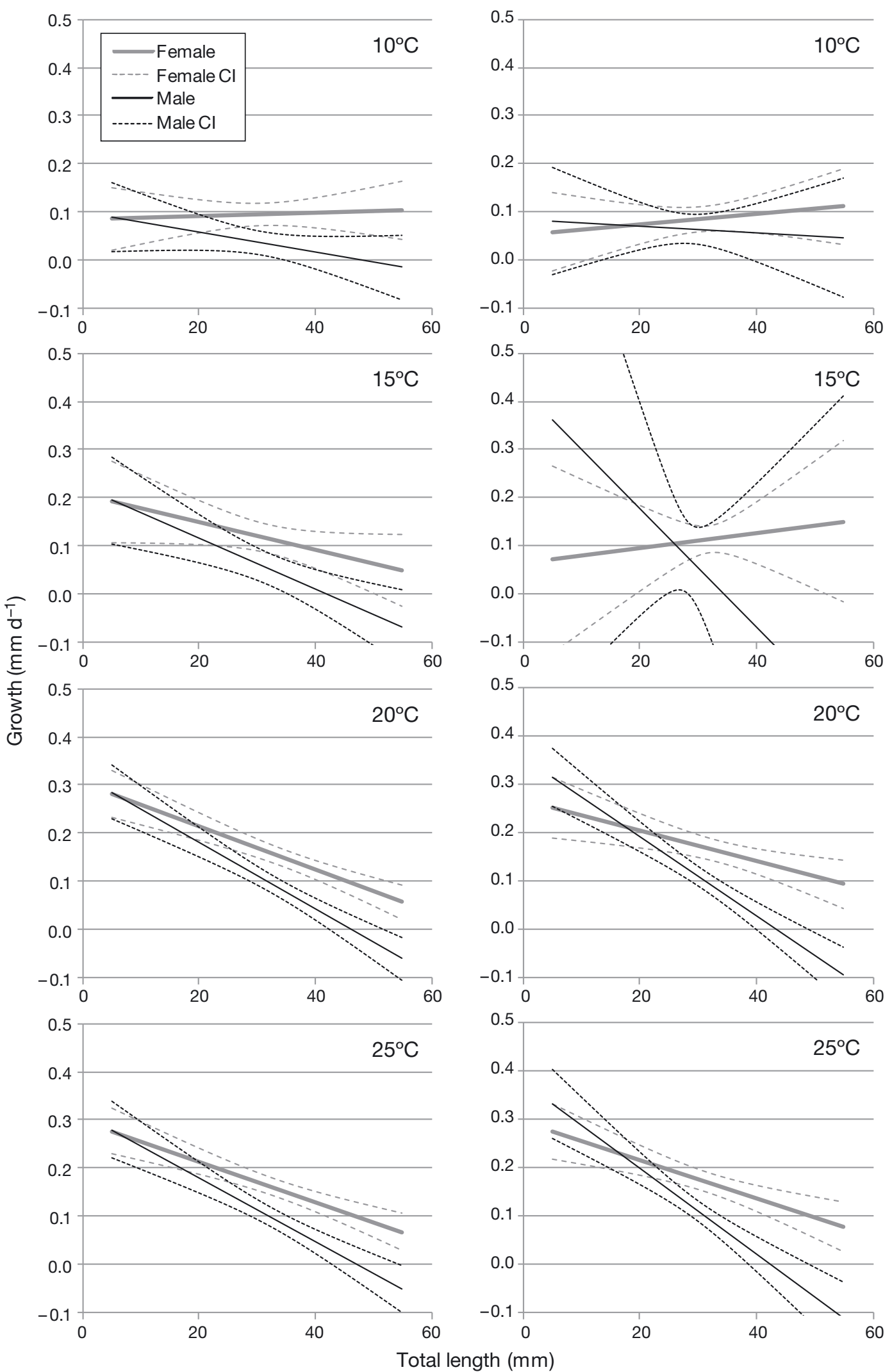

Fig. 2. Crangon crangon. Growth predictions for the Minho data, using the global (left) and site-/sex-specific (right) mixed effects models, applied to different shrimp sexes and experimental temperatures 

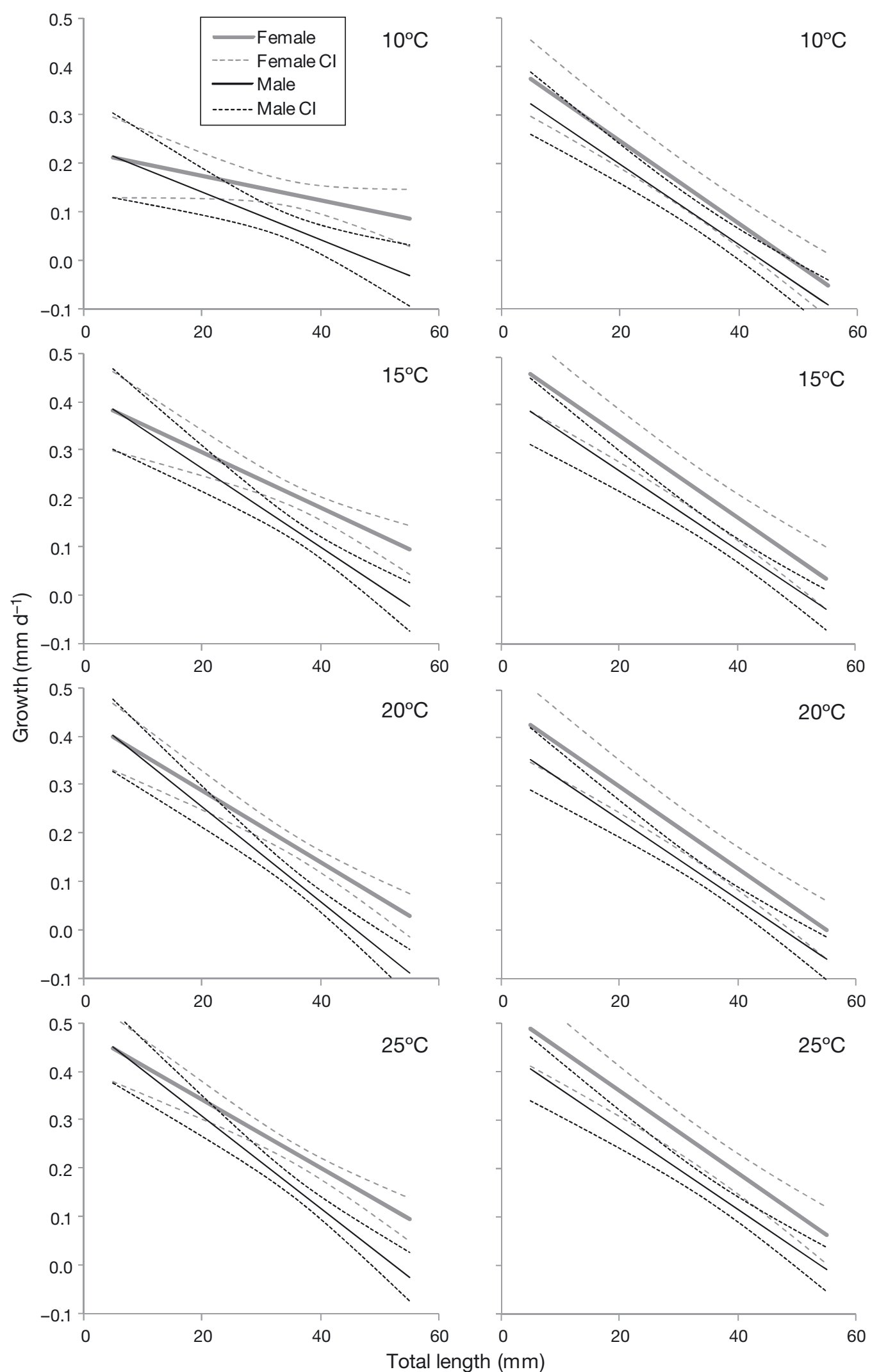

Fig. 3. Crangon crangon. Growth predictions for the Valosen data, using the global (left) and site-/sex-specific (right) mixed effects models, applied to different shrimp sexes and experimental temperatures 

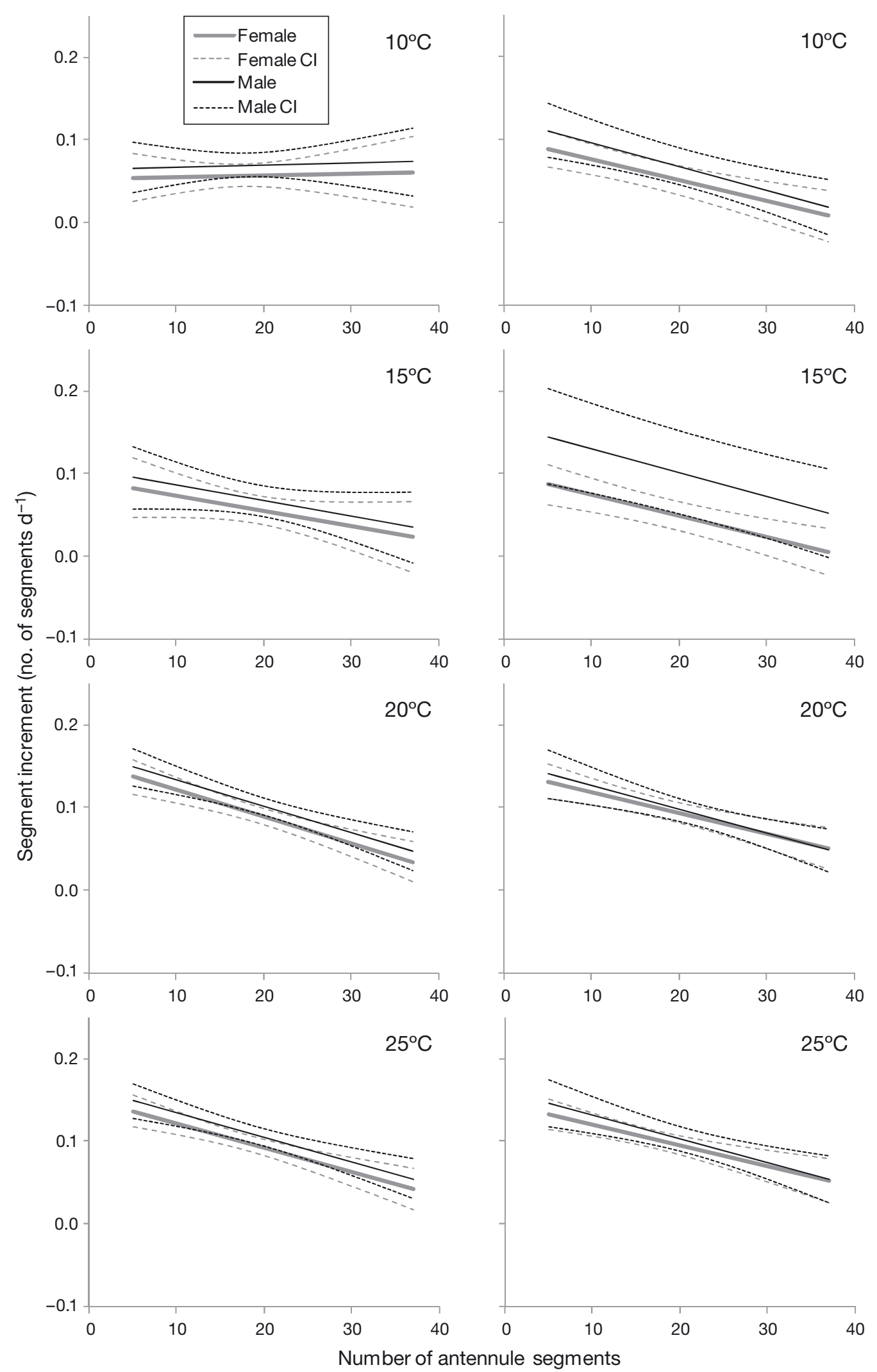

Fig. 4. Crangon crangon. Segment-increment predictions for the Minho data, using the global (left) and site-/sex-specific (right) mixed effects models, applied to different shrimp sexes and experimental temperatures 

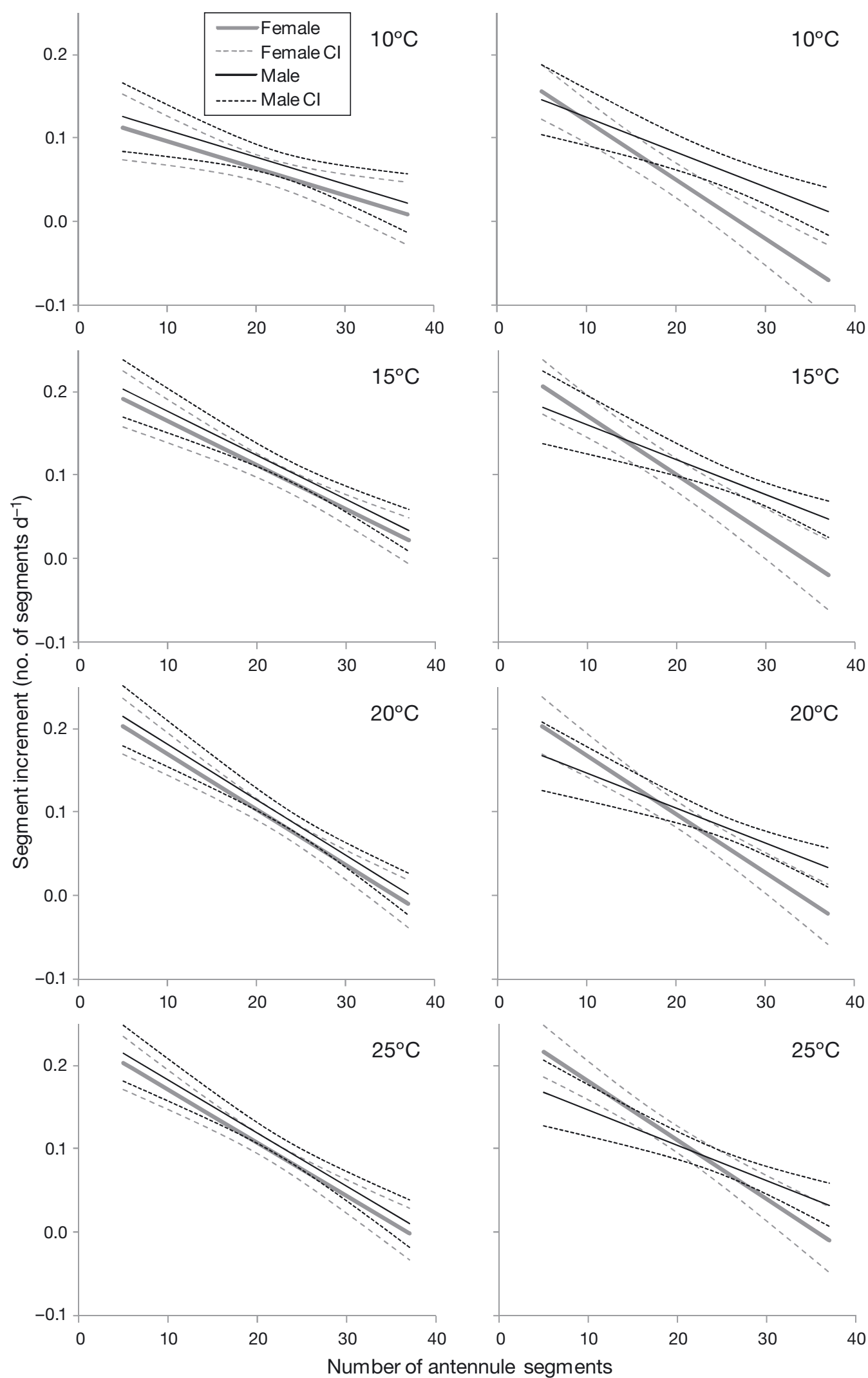

Fig. 5. Crangon crangon. Segment-increment predictions for the Valosen data, using the global (left) and site-/sex-specific (panel) mixed effects models, applied to different shrimp sexes and experimental temperatures 
to 5, right column). However, some slopes, particularly for low temperatures, diverged, and the GR model for female shrimp from Minho resulted in very variable and unreliable predictions for $15^{\circ} \mathrm{C}$ temperature (Fig. 2). Contrary to the global SI model, the Minho-female SI model predicted less SI with increasing SN (Fig. 4). Furthermore, site- and sexspecific SI model predictions diverged more between sexes than global SI model predictions.

SI models performed generally worse than GR models. Goodness-of-fit depended on shrimp origin, sex and temperature (Table 5). Both global and site/sex-specific model predictions fitted the data from Valosen better than those from Minho. The best fitting GR and SI predictions were those for female shrimp from Valosen. Except for female shrimp from Valosen, predictions were worse for high experimental temperatures. Many SI model predictions had a very poor fit, particularly 2 of the site-/sex-specific SI models, the Minho-female and Minho-male models, which showed nearly no correlation between observed and fitted values for the experimental temper- ature of $10^{\circ} \mathrm{C}$. Overall, sub-setting the data did not achieve better model fits. We therefore chose to use the global GR and SI model predictions for the age estimations.

\section{Estimated age curves}

The shape of both age-growth and age-segmentincrement curves was generally similar to that of a typical von Bertalanffy curve (Figs. 6 \& 7). Young shrimp were predicted to grow very fast in the beginning, slowing down with increasing age and reaching a threshold of maximum shrimp size. Growth rates and size thresholds were larger for female than male shrimp. Three models had positive slopes: GR-Minho-female- $10^{\circ} \mathrm{C}$; SI-Minho-female; and SIMinho-male- $10^{\circ} \mathrm{C}$. In terms of SI with age, we observed similar patterns but less pronounced differences between sexes. Male shrimp tended to have more segments than female shrimp at the same age, though CI intervals are very overlapped.

The differences between fast- and slow-growing shrimp were often considerable, varying between 5 and $36 \mathrm{~mm}$ TL and between 5 and 19 antennule segments at $1 \mathrm{yr}$ of age (Figs. $6 \& 7$, Table 6).

\section{Shrimp age estimates}

Comparing the ages predicted by the growth models and the segmentincrement models (Figs. 8 \& 9), GR models tended to predict slightly lower ages for young shrimp but clearly higher ages for older shrimp, particularly those older than 1 yr. For $47 \%$ of the age estimates, GR-based age predictions were lower than those for the fast-growing shrimp according to the SI models. For $39 \%$ of the age estimates, the SI-based age predictions were higher than those for the slow-growing shrimp according to the GR models.

There was one clear outlier from Valosen, a male shrimp kept at $20^{\circ} \mathrm{C}$ that showed a much higher predicted age based on the GR model than on the SI model for its (last) fourth and fifth moult. There was a second case of exceptionally high GR-model predicted 

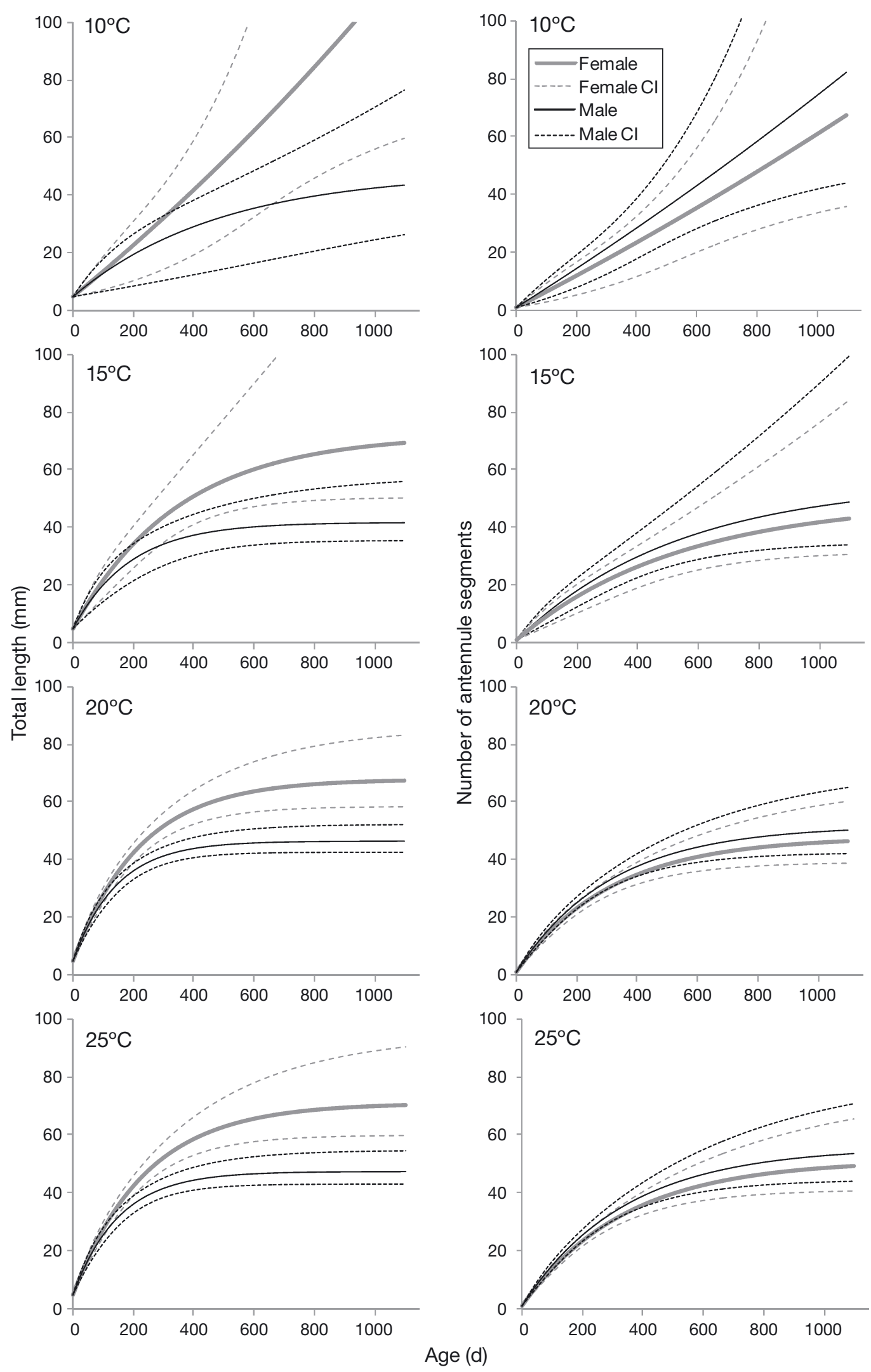

Fig. 6. Crangon crangon. Estimated age-growth (left) and estimated age-segment-increment (right) curves for the Minho data, considering shrimp sex and experimental temperatures 

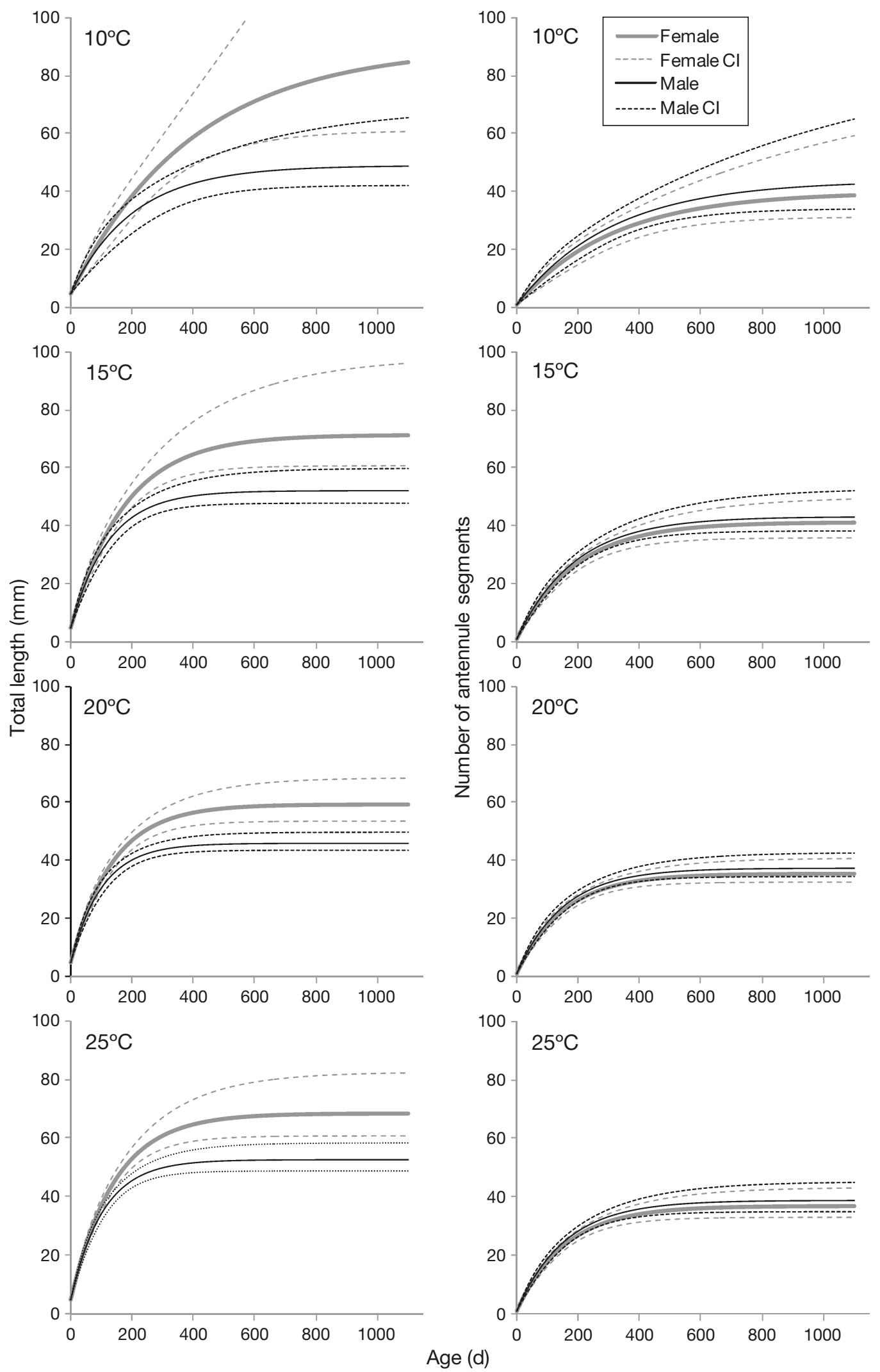

Fig. 7. Crangon crangon. Estimated age-growth (left) and estimated age-segment-increment (right) curves for the Valosen data, considering shrimp sex and experimental temperatures 
Table 6. Crangon crangon. Differences in predicted total shrimp length $(\Delta \mathrm{L})$ and in the predicted number of antennule segments $(\Delta \mathrm{SN})$ between fast- and slow-growing shrimps at the age of 1 and $2 \mathrm{yr}$, considering shrimp origin, sex and temperature treatment

\begin{tabular}{|c|c|c|c|c|c|c|}
\hline \multirow[t]{2}{*}{ Origin } & \multirow[t]{2}{*}{ Sex } & \multirow{2}{*}{$\begin{array}{l}\text { Temp } \\
\left({ }^{\circ} \mathrm{C}\right)\end{array}$} & \multicolumn{2}{|c|}{$\Delta \mathrm{L}(\mathrm{mm})$} & \multicolumn{2}{|c|}{$\Delta \mathrm{SN}$} \\
\hline & & & $1 \mathrm{yr}$ & $2 y r$ & $1 \mathrm{yr}$ & $2 y \mathrm{r}$ \\
\hline \multirow[t]{8}{*}{ Minho } & Female & 10 & 36 & 109 & 19 & 52 \\
\hline & & 15 & 22 & 57 & 14 & 28 \\
\hline & & 20 & 10 & 20 & 7 & 15 \\
\hline & & 25 & 12 & 24 & 7 & 17 \\
\hline & Male & 10 & 25 & 36 & 19 & 62 \\
\hline & & 15 & 14 & 18 & 14 & 34 \\
\hline & & 20 & 7 & 9 & 7 & 16 \\
\hline & & 25 & 8 & 11 & 8 & 18 \\
\hline \multirow[t]{8}{*}{ Valosen } & Female & 10 & 22 & 64 & 10 & 18 \\
\hline & & 15 & 17 & 31 & 7 & 11 \\
\hline & & 20 & 10 & 14 & 5 & 7 \\
\hline & & 25 & 13 & 20 & 6 & 9 \\
\hline & Male & 10 & 12 & 18 & 10 & 20 \\
\hline & & 15 & 8 & 11 & 7 & 12 \\
\hline & & 20 & 5 & 6 & 5 & 7 \\
\hline & & 25 & 8 & 10 & 6 & 9 \\
\hline
\end{tabular}

age, for the fourth and fifth moults from a male shrimp from Minho, kept at $10^{\circ} \mathrm{C}$. But overal the GRmodel age predictions for male shrimp from Minho at $10^{\circ} \mathrm{C}$ tended to be much higher than the SI-model age predictions. On the other hand, at $15^{\circ} \mathrm{C}$, male shrimp ages predicted by the GR model were very low in comparison to the SI model predictions.

\section{DISCUSSION}

Accurate age determination of Crangon crangon is a relevant issue for fisheries management. Knowing the correct age enables us to construct growth curves, which are necessary to determine the species' productivity and, hence, to follow their variability over time. It further allows determining the species' longevity and mortality rates, both due to natural causes and to fisheries, and to evaluate the stock structure, not only in terms of age, but also considering the age at certain life stages (settlement, maturation).

The frequently used length-growth method is, though usually not recognized as such, a simple empirical approach. Authors often empirically relate a certain age to a certain size, considering mean development time of different stages

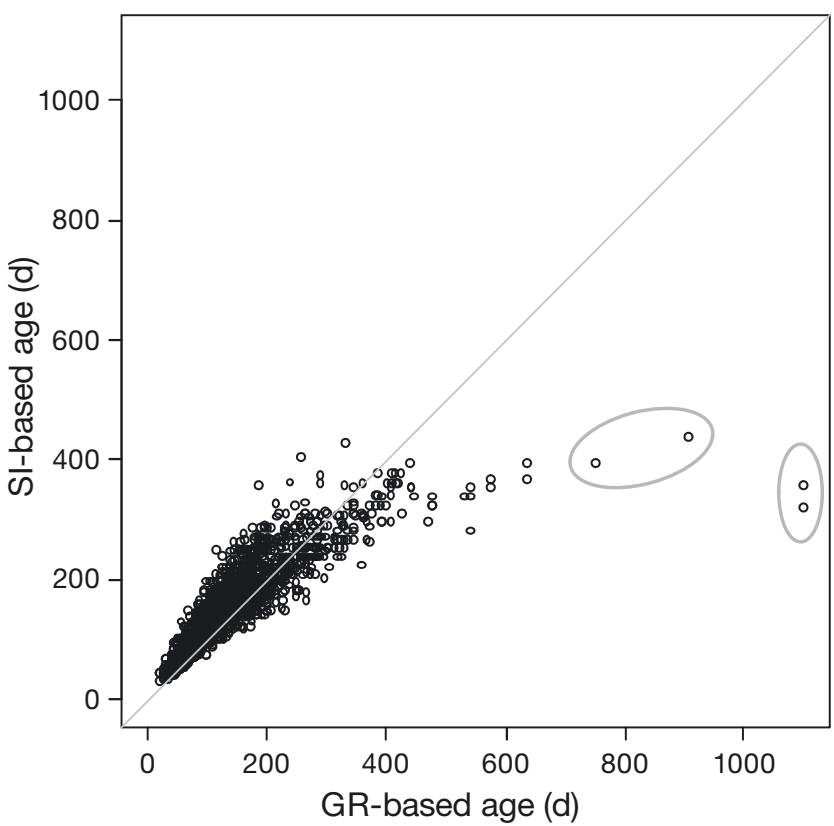

Fig. 8. Crangon crangon. Shrimp-length- and antennulesegment-dependent age estimates for the experimental data (i.e. initial intermoult period shrimp size and antennule segment number) based on the previously established age curves (Figs. 6 \& 7). The encircled points correspond to estimates for the fourth and fifth moults of 2 individual shrimps. GR: growth; SI: segment increment

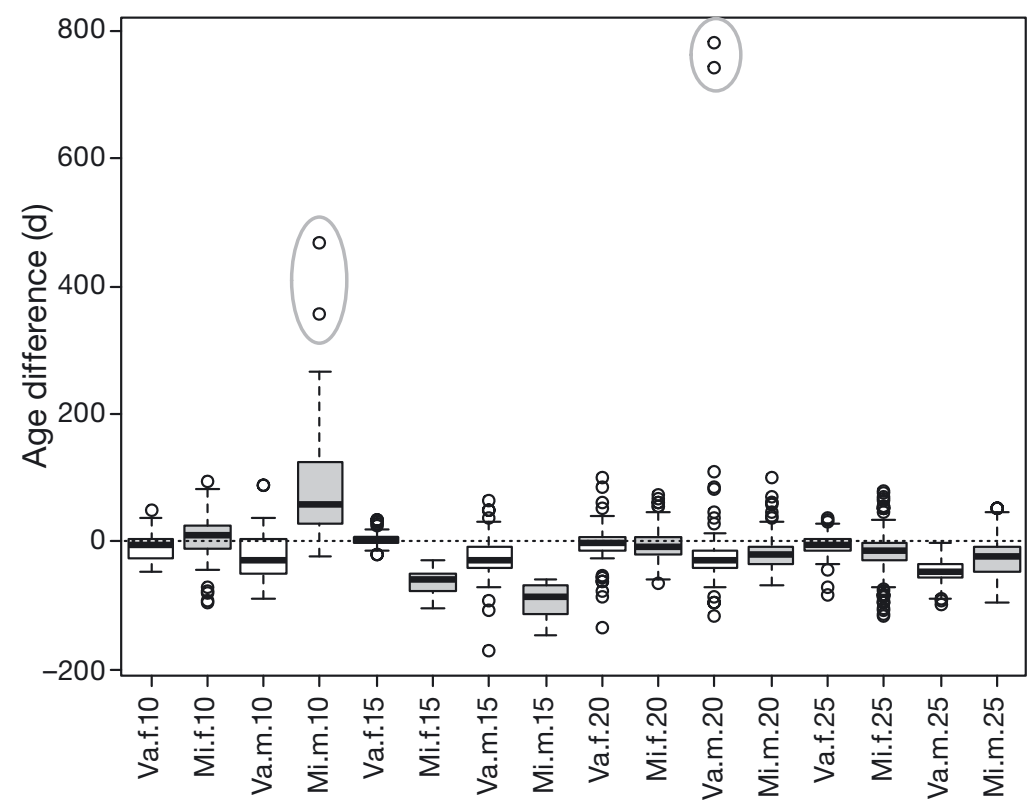

Fig. 9. Crangon crangon. Differences between age estimates based on shrimp length and shrimp-antennule segments, grouped per shrimp origin (Va.: Valosen, white; Mi.: Minho, grey), sex (f: female; m: male) and culture temperature (in ${ }^{\circ} \mathrm{C}$ ). Thick black lines show median values; rectangles show the first to third inter-quartile range (IQR); whiskers go from minimum to maximum values, except for outliers (at distances from the box limits that exceed $1.5 \times \mathrm{IQR}$ ), which are presented as circles. The encircled outliers correspond to estimates for the fourth and fifth moults of 2 individual shrimps 
observed under controlled conditions and a growth rate that is either assumed or determined, or estimated through modelling (Kuipers \& Dapper 1984, Temming \& Damm 2002). However, the lengthgrowth method does not effectively include the determination of the shrimps' age. Several examples can be found in the literature: some refer to the shrimps' longevity estimated by their size and others refer to age at maturity or age at which some particular event in the life cycle, e.g. settlement, takes place. However the species' long reproduction period allied to differential individual growth can result in the coexistence of cohorts of mixed age at the same length. This is, for example, reflected in the uncertainty about the species' maximum age, which is considered to vary between 1 and 5 yr (Havinga \& Willer 1929, Havinga 1930, Lloyd \& Yonge 1947, Tiews 1954, Oh et al. 1999). More recently, Perger \& Temming (2012) proposed a new method to determine in situ growth rates based on the dry weight condition before and after a moult event. Despite promising to discriminate growing shrimps from the starving ones that will not contribute to population growth, again, this method does not effectively determine the age of shrimps.

In the present work, shrimps showed a great individual variability in both increase in total length and antennule segment increments. This variability resulted in significant random effects (individual shrimps) in both models. Such considerable individual variability in growth patterns had previously been described for the same studied populations (Campos et al. 2009), as well as for shrimps from the North Sea (Hufnagl \& Temming 2011a) and from other locations (for a summary table see Hufnagl \& Temming 2011b). As a consequence of this individual variability, field populations consist as a mix of fast- and slow-growing shrimps. This was reflected in our raw data as well as in the growth and antennule-segment-increment models and their predictions. Moreover, contradicting Tiews (1954), observations included numerous moults with zero segment increment; the number of segments was, hence, not directly related to the number of moults. Analogously, the size increment was often zero, resulting in moults with no growth at all. Again, this reveals a high variability in growth and limits the use of both age estimation methods.

Besides the effect of 'individuality', site of origin, sex, total length, number of segments and water temperature were confirmed to influence growth, both in length and in segment-increment models, and often to interact. These growth-rate patterns were consistent with the findings of an earlier study (Campos et al.
2009), in which moult size increments, duration of the intermoult period and growth rates were investigated, whereby growth was related to shrimp length and to temperature by the simple equation: $\mathrm{GR}=a+$ $b \mathrm{~T}-c \mathrm{~L}$, with parameters $a, b$ and $c$ depending on shrimp origin and sex. The 'site of origin' effect highlights the importance of validating any age estimation method before its application. Despite the scarce knowledge on trends in the brown shrimp's life cycle across the species' geographic range, some tendencies in its growth have been pointed out (see 'Introduction'). Given the latitudinal trends observed in the growth rate, either counteracting the thermal gradient (Campos et al. 2009) or not (Viegas et al. 2012), age estimation methods have a local scale. No single equation will generalize growth adequately, at least for distant populations. Other growth-related differences between populations that can influence age estimates besides growth rate, such as longevity, size or age at maturation, and settlement size or age, should be explored in future studies.

The temperature's influence on growth was amply discussed by Campos et al. (2009). On the one hand, the size increment at moult was found to be poorly influenced by temperature, whereas the duration of the intermoult period was much more consistently affected. This has implications for age estimation, because the time elapsed between 2 consecutive moults is then expected to vary according to temperature, justifying the presence of temperature as a parameter in the present models. On the other hand, a 'latitudinal compensation' in growth was observed, whereby northern shrimps were physiologically better prepared to grow faster than southern shrimps at the same temperature. An explanation for this trend may be found in the limited time frame available for growth, i.e. the length of the growing season, which is shorter at higher latitudes and may be compensated by higher growth rates. This compensation also has implications for age estimation, because populations adapted to different temperature regimes will grow differently, stressing once more the need of validating age estimation models for local conditions. Although 'latitudinal compensation' was partly corroborated by the models, as the northern population showed faster growth at higher temperatures than the southern one, the model predictions for the Minho population kept at lower temperatures were too variable to effectively confirm this assumption.

Other factors have been reported to influence growth, including the shrimps' cohort and food quality (Meixner 1966, Oh \& Hartnoll 2000, Hufnagl \& Temming 2011a). In the present study, all observed 
shrimps were collected in the same month and fed with mussel meat, reducing the effect of these 2 variables, though probably not eliminating their influence. Despite its good quality for human consumption, commercial mussel meat is probably not a balanced diet for shrimp compared to their natural, diversified diet. In the same way, physiological and/or behavioural changes associated with the onset of sexual maturity can affect growth and be a source of variability. During maturation and reproduction, part of the ingested energy is allocated to gonadal development. Moreover, ovigerous females cannot moult before the eggs hatch (Boddeke 1966), and therefore growth will be conditioned.

Both age-estimation methods produced growth curves with a shape close to a typical von Bertalanffy growth curve, especially using the Valosen dataset: faster growth in the beginning, slowing down with increasing age until a maximum shrimp size/number of antennule segments is reached. The growth rate was greater for females than for males and for higher temperatures, as commonly reported in previous studies (see Campos et al. 2009, Hufnagl \& Temming 2011a), and the maximum size was also larger for females. In contrast, maximum segment number was larger for males than for females, as was also found by Tiews (1954). The brown shrimp is considered a facultative protandric hermaphrodite, changing from male to female (Schatte \& Saborowski 2006), with little impact on the species' population dynamics (Hufnagl et al. 2010). In the present study, sex was checked a minimum of 2 to 3 times for each shrimp (at the beginning and end of the trials, and when the exhuvium was found in a well-preserved condition). A few shrimps that might have changed sex were identified and excluded from the analysis. Nevertheless, it is possible that a few were incorrectly sexed as females in the first assessment and that, hence, no sex change was detected later on. This would have a small but unknown impact on the results, accounting for part of the observed variability.

However, the 2 models resulted in considerably different age estimates, particularly for older shrimps, i.e. shrimps of larger size or with more antennule segments. This means that shrimps of different ages may have similar sizes, which, in fact, is likely to be true to a certain extent as different cohorts coexist in the same population due to the prolonged reproduction period (see for example Cattrijsse et al. 1997, Cowx et al. 1998, Oh et al. 1999, Viegas et al. 2007). Analogously they may have similar segment numbers. Even if shrimp have undergone the same number of moults, intermoult period duration varies dramatically depending on temperature conditions (Campos et al. 2009, Hufnagl \& Temming 2011a); it is therefore also possible that the segment number differs in shrimps of the same age. It is, however, unfortunately, not possible to determine the real age of the shrimps or to confirm the estimated ages.

So the question remains: Is the number of segments a better age predictor than length? For the populations and conditions tested in the present study, segment-increment models had, in general, worse fits than the growth-rate models. It is true that, contrary to the growth rate, no negative segment increase was observed. But, contrary to Tiews' (1954) observations, our data showed high percentages of zero increment, which limit the use of segment number as an age predictor.

Up to the present, and despite the success of some researchers in hatching eggs in the laboratory (Criales \& Anger 1986, Dalley 1980) and growing juveniles to the adult stage (see for example Campos et al. 2009, Hufnagl \& Temming 2011a), completion of the entire shrimp life cycle, especially the passage from larvae to juveniles, under controlled conditions has not been achieved. If, in the future, successful completion of the shrimp's life cycle in the laboratory is achieved, growth in relation to age, both in length and in number of antennule segments, could be monitored and correctly quantified. This would further allow control of the 'individuality' effect. A combination of the 2 approaches might then be used to improve age estimates, in a more complex model approach. Ultimately, validations for each population would be necessary, as the models have been proven to be site specific, at least for geographically distant populations. Validation would, for instance, be interesting for the North Sea population, which was not investigated in this study, but is, in contrast to the 2 studied populations, commercially exploited. Though high individual variability is also expected for North Sea shrimps, the extent of the fast- versus the slowgrowing fractions of the population is unknown. There might be a reduction in variability due to the fact that fisheries selectively remove larger animals ( $\geq 50 \mathrm{~mm}$ total length) and, hence, most likely, the fast-growing ones, which, in turn, might affect the population's age-growth curve.

Acknowledgements. The authors thank the staff from HIBO and CIIMAR who provided the means to accomplish this study, namely S. Skreslet, H. Witte, M. Krostad, E. Tryggestad, T. Skålsvik, H. Santos, J. C. Antunes, E. Martins and L. Guilhermino, and the students who collaborated in rearing the shrimps, especially E. Dias, S. Santos, C. Mendes and M. João Almeida. Thanks are also due to the 4 anony- 
mous referees for the critical contributions to the manuscript. This work was supported by national funds from the FCT (Foundation for Science and Technology) through the grants SFRH/BD/11321/2002 and SFRH/BPD/71205/2010, and the projects POCI/CLI/61605/2004 and PesT-C/Mar/ LA0015/2011, by the EU RECLAIM project (REsolving CLimAtic IMpacts on fish stocks), EC Contract Number 044133, and by the European Regional Development Fund (ERDF) through the COMPETE-Operational Competitiveness Programme. The experiments complied with the current laws of Portugal and Norway.

\section{LITERATURE CITED}

Beukema JJ (1992) Dynamics of juvenile shrimp Crangon crangon in a tidal-flat nursery of the Wadden Sea after mild and cold winters. Mar Ecol Prog Ser 83:157-165

Boddeke R (1966) Sexual cycle and growth of brown shrimp (Crangon crangon). ICES C M 1966/M:6:1-2

Boddeke R, Driessen G, Doesburg W, Ramaekers G (1985) Settlement and growth of brown shrimp (Crangon crangon) in a coastal area. ICES CM 1985/K:16

Bosley KM, Dumbauld BR (2011) Use of extractable lipofuscin to estimate age structure of ghost shrimp populations in west coast estuaries of the USA. Mar Ecol Prog Ser 428:161-176

> Burrows MT, Gontarek SJ, Nash RDM, Gibson RN (2001) Shrimp predation on 0-group plaice: contrasts between field data and predictions of an individual-based model. J Sea Res 45:243-254

> Campos J, Van der Veer HW (2008) Autecology of Crangon crangon (L.) with an emphasis on latitudinal trends. Oceanogr Mar Biol Annu Rev 46:65-104

Campos J, Freitas V, Pedrosa C, Guillot R, Van der Veer HW (2009) Latitudinal variation in growth of Crangon crangon (L.): Does counter-gradient growth compensation occur? J Sea Res 62:229-237

Campos J, Bio A, Cardoso JFMF, Dapper R, Witte JIJ, Van der Veer HW (2010) Fluctuations on the brown shrimp Crangon crangon (Crustacea: Caridea) abundance in the western Dutch Wadden Sea, The Netherlands. Mar Ecol Prog Ser 405:203-219

Castro M, Encarnação P, Tully O (2002) The effect of dietary antioxidants on lipofuscin accumulation in the crustacean brain. J Exp Mar Biol Ecol 269:53-64

Cattrijsse A, Dankwa HR, Mees J (1997) Nursery function of a tidal marsh for the brown shrimp Crangon crangon. J Sea Res 38:109-121

> Cowx, IG, O'Grady KT, Del Norte-Campos AGC, Temming A (1998) Population dynamics of the brown shrimp Crangon crangon L., in shallow areas of the German Wadden Sea. Fish Manag Ecol 5:303-322

Criales MM, Anger K (1986) Experimental studies on the larval development of the shrimps Crangon crangon and C. almanii. Helgol Wiss Meeresunters 40:241-265

Dalley R (1980) The survival and development of the shrimp Crangon crangon (L.) reared in the laboratory under non-circadian light-dark cycles. J Exp Mar Biol Ecol 47: 101-112

Duran M (1997) The ecology of brown shrimp Crangon crangon (L.) in the Wash. PhD thesis, University of East Anglia, Norwich

Gelin A, Crivelli AJ, Rosecchi E, Kerambrun P (2000) Is the brown shrimp Crangon crangon (L.) population of the
Vaccarès lagoon (Camargue, France, Rhône delta) an annual population? C R Acad Sci III 323:741-748

Hartnoll RG (2001) Growth in Crustacea-twenty years on. Hydrobiologia 449:111-122

> Harvey HR, Ju SeJ, Son SK, Feinberg LR, Shaw CT, Peterson WT (2010) The biochemical estimation of ageing euphausiids: laboratory calibration and field comparisons. Deep-Sea Res II 57:663-671

Havinga B (1930) Der Granat (C. vulgaris, Fabr.) in den holländischen Gewässern. J Cons Int Explor Mer 5:57-87

Havinga BA, Willer A (1929) Krebse und Weichtiere. Schweitzerbart'sche Verlagsbuchhandlung, Stuttgart

Henderson PA, Holmes RHA (1987) On the population biology of the common shrimp Crangon crangon (L.) (Crustacea: Caridea) in the Severn Estuary and Bristol Channel. J Mar Biol Assos UK 67:825-847

Hufnagl M, Temming A (2011a) Growth in the brown shrimp Crangon crangon. I. Effects of food, temperature, size, gender, moulting, and cohort. Mar Ecol Prog Ser 435: 141-154

Hufnagl M, Temming A (2011b) Growth in the brown shrimp Crangon crangon. II. Meta-analysis and modelling. Mar Ecol Prog Ser 435:155-172

Hufnagl M, Temming A, Danhardt A (2010) Hermaphroditism in brown shrimp: lessons from field data and modelling. Mar Biol 157:2097-2108

- Kilada R, Sainte-Marie B, Rochette R, Davis N, Vanier C, Campana $S$ (2012) Direct determination of age in shrimps, crabs, and lobsters. Can J Fish Aquat Sci 69: 1728-1733

Kuipers BR, Dapper R (1984) Nursery function of Wadden Sea tidal flats for the brown shrimp Crangon crangon. Mar Ecol Prog Ser 17:171-181

Lloyd AJ, Yonge CM (1947) The biology of Crangon vulgaris L. in the Bristol Channel and the Severn estuary. J Mar Biol Assoc UK 26:626-661

Luttikhuizen PC, Campos J, Bleijswijk J, Peijnenburg KTCA, Van der Veer HW (2008) Phylogeography of the common shrimp, Crangon crangon (L.) in European waters. Mol Phylogenet Evol 46:1015-1030

Marchand J (1981) Observations sur l'écologie de Crangon crangon et Palaemon longirostris H. Milne Edwards (Crustacea, Decapoda, Natantia) Estuaire interne de la Loire France. Vie Milieu 31:83-92

Meixner R (1966) The effects of food supply on moulting, growth and spawning of the shrimp Crangon crangon (L.). ICES CM 1966/M:5:1-7

> Oh CW, Hartnoll RG (2000) Effects of food supply on the growth and survival of the common shrimp, Crangon crangon (L.) (Decapoda: Caridea). Crustaceana 73:83-99

> Oh CW, Hartnoll RG, Nash RDM (1999) Population dynamics of the common shrimp, Crangon crangon (L.), in Port Erin Bay, Isle of Man, Irish Sea. ICES J Mar Sci 56: 718-733

Perger R, Temming A (2012) A new method to determine in situ growth rates of decapod shrimp: a case study with brown shrimp Crangon crangon. Mar Biol 159:1209-1222

Pinheiro JC, Bates DM (2000) Mixed-effects models in S and S-PLUS. Springer, New York, NY

R Development Core Team (2008) R: a language and environment for statistical computing. R Foundation for Statistical Computing, Vienna

> Reyss JL, Schmidt S, Latrouite D, Floris S (1996) Age determination of crustaceans using ${ }^{228} \mathrm{Th} /{ }^{228} \mathrm{Ra}$ measurements by ultra low level gamma spectroscopy. Appl Radiat Isot 
47:1049-1053

Schatte J, Saborowski R (2006) Change of external sexual characteristics during consecutive moults in Crangon crangon L. Helgol Mar Res 60:70-73

Schockaert E (1968) Contribuition à l'étude de la croissance et de la reproduction de la crevette grise (Crangon crangon L.) au large de la côte belge. Biologisch Jaarb 36: 169-179

Temming A, Damm U (2002) Life cycle of Crangon crangon in the North Sea: a simulation of the timing of recruitment as a function of the seasonal temperature signal. Fish Oceanogr 11:45-58

Tiews K (1954) Die biologischen Grundlagen der Büsumer

Editorial responsibility: Bernard Sainte-Marie, Mont-Joli, Quebec, Canada
Garnelenfischerei. Ber Deut Wiss Kommiss 13:235-269

> Viegas I, Martinho F, Neto J, Pardal M (2007) Population dynamics, distribution and secondary production of the brown shrimp Crangon crangon (L.) in a southern European estuary. Latitudinal variations. Sci Mar 71:451-460

Viegas I, Marques SC, Primo AL, Martinho F, Azeiteiro UM, Pardal M (2012) Life history strategy of a southern European population of brown shrimp (Crangon crangon L.): evidence for latitudinal changes in growth phenology and population dynamics. Mar Biol 159:33-43

Zuur AF, Ieno EN, Walker NJ, Saveliev AA, Smith GM (2009) Mixed effects models and extensions in ecology with R. Springer, New York, NY

Submitted: December 11, 2012; Accepted: July 12, 2013

Proofs received from author(s): September 20, 2013 